\title{
Helicobacter pylori increases expression of proapoptotic markers Fas and FasL on CD4 lymphocytes in children
}

\author{
Aldona Kotłowska-Kmieć ${ }^{\bowtie}$, Alicja Bąkowska², Adam Szarszewski³, Barbara \\ Kamińska ${ }^{3}$, Grażyna Łuczak ${ }^{3}$, Wojciech Radys ${ }^{3}$, Piotr Landowski ${ }^{3}$ Jacek Brodzicki ${ }^{3}$, \\ Maria Korzon ${ }^{3}$ and Anna Liberek ${ }^{3}$ \\ ${ }^{1}$ Children's Hospital, Gdansk, Poland; ${ }^{2}$ Department of Immunopathology, ${ }^{3}$ Chair and Department of Paediatrics, \\ Paediatric Gastroenterology, Hepatology and Nutrition, Medical University of Gdańsk, Gdańsk, Poland
}

Received: 23 April, 2009; revised: 14 June, 2009; accepted: 22 June, 2009

available on-line: 02 July, 2009

\begin{abstract}
The pathomechanism of Helicobacter pylori action upon gastric mucosa and its role in the pathogenesis of gastritis have not been fully elucidated. The aim of this study was to evaluate the most prevalent lymphocyte subpopulations of the gastric mucosa in gastritis in children, as well as to evaluate the expression of Fas and Fas ligand receptors (FasL), periapoptotic markers of gastric mucosa lymphocytes before and after H. pylori eradication. Forty nine patients aged 6 to 17 years, investigated due to chronic abdominal pain, were studied. The obtained tissue samples were analysed by immunohistochemistry. Different lymphocyte subsets were quantified on the basis of surface antigen expression (CD3, CD4, CD8, CD20), secreted cytokines (IL-4, IL-6, IFN $\gamma$ ) and Fas and FasL proteins in the gastric mucosa. $B$ and $T$ helper lymphocytes were found to play a major role in the inflammatory infiltration in the gastric mucosa in children during $\mathrm{H}$. pylori infection. Their expression was found to decrease after eradication. The enhanced expression of Fas receptor on lymphocytes before treatment and a decrease of this expression after eradication of $\mathrm{H}$. pylori were shown. It was demonstrated that there is a correlation between CD4 and Fas receptor expression that may induce apoptosis of the helper lymphocytes in infected children.
\end{abstract}

Keywords: H. pylori, lymphocyte, T cell, apoptosis, Fas, FasL

\section{INTRODUCTION}

Nowadays, it is accepted that as a result of Helicobacter pylori damaging action upon gastric mucosa the host's immunological mechanisms are activated (Dohil et al., 1999). The lymphocyte subpopulation that plays the dominant role in inflammatory infiltration in children is still uncertain. Persistence of the inflammation, in spite of the induction of the host's immunological reactions, suggests that $H$. pylori has developed some mechanisms of evading immunosurveillance (Ernst \& Gold, 1999; Wang et al., 2001; Krauss- Etschmann et al., 2005). One of them might be apoptosis. H. pylori induced apoptosis of epithelial cells and lymphocytes appears to be enhanced by the expression of the so called "death receptors", including the Fas (CD95) and Fas ligand (CD95L) system (Souza et al., 2006; Wisniewski et al., 2008). A few recently published studies investigating paediatric population have shown an increase in the apoptosis index and proliferation of epithelium cells in $H$. pylori infected children as compared to healthy children. This suggests that eradication of $H$. pylori diminishes this process (Houghton et al., 1999; Tytgat, 1992; Singh et al., 2006). However, H. pylori might delay spontaneous lymphocyte apoptosis and prolong the survival of these cells or even inhibit T-cell proliferation (Schmees et al., 2007). It can

${ }^{\square}$ Corresponding author: Aldona Kotłowska-Kmieć, Children's Hospital, Polanki 119, 80-308 Gdańsk, Poland; tel.: (48) 58 520 9315; fax: (48) 58552 4741; e-mail: akmiec@amg.gda.pl

Abbreviations: Fas, receptor Fas; FasL, receptor Fas ligand; CD, cluster of differentiation antygen; IL, interleukin; INF, interferon; PAP, peroxidase-antiperoxidase. 
also enhance the "fratricidal" death of lymphocytes by apoptosis, by concurrent increase in the expression of Fas and FasL on their surface (Sommer et al., 1998; Houghton et al., 1999; Koyama, 2000; Wang et al., 2001). This may be another step towards solving the problem of eradication and elimination of the bacteria.

The aim of the study was to evaluate the prevalence of lymphocyte subpopulations and periapoptotic receptors Fas and FasL in the gastric mucosa during $H$. pylori infection and after eradication treatment in children. We also made an attempt to answer the question which of the lymphocyte subsets predominantly enter the apoptosis induction phase.

\section{PATIENTS AND METHODS}

The study group consisted of 49 patients referred to the Endoscopy Unit of the Chair and Department of Paediatrics, Paediatric Gastroenterology, Hepatology and Nutrition of the Medical University of Gdańsk (Poland). They were examined because of chronic abdominal pain which was an indication for upper gastrointestinal endoscopy (gastroduodenofiberoscope GIF 160-Olympus).

Children with a history of allergy, intake of antibiotics or anti-acid drugs within 30 days preceding the examination or with either primary or secondary malabsorption syndrome were excluded.

Forty nine patients aged 6 to 17 years (mean age $12.86 \pm 2.59)$ were examined. Thirty three of them were girls aged 6 to 17 years (mean age $12.97 \pm 2.96$ ) and 16 of them were boys aged 9 to 15 years (mean age $12.63 \pm 1.63$ ).

Patients were divided into three groups:

Group I -12 children (7 girls and 5 boys) aged 7 to 17 years (mean age $13.17 \pm 2.55$ ) without gastritis in histological examination and without H. pylori infection,

Group II -10 children ( 5 girls and 5 boys) aged 10 to 17 years (mean age $13.6 \pm 2.17$ ) with chronic gastritis and without $H$. pylori infection,

Group III -27 children ( 21 girls and 6 boys) aged 6 to 17 years (mean age $12.45 \pm 2.75$ ) with chronic gastritis and with $H$. pylori infection and,

Group IIIA - 11 children (6 girls and 5 boys) aged 9 to 17 years (mean age $13 \pm 2.72$ ) from group III after eradication treatment.

Complete eradication was obtained in 5 children from this group. In the remaining 6 patients the bacteria were still detectable in spite of treatment.

In all patients included in this study upper gastrointestinal endoscopy, urease test (Clo-test) and histological examination of the gastric and duode- nal biopsies were performed in order to assess the grade of gastritis and duodenitis according to the Sydney classification (Misiewicz et al., 1994; Dixon et al., 1996). All patients had macroscopic lesions of gastric and duodenal mucosa in endoscopic examination and were submitted to the routine therapy ${ }^{1}$. Mild and moderate gastritis was mainly observed in group I and II, while moderate and serious gastritis was found in group III.

Children with gastritis and co-existing $H$. pylori infection were subjected to triple therapy: omeprazole for 4 weeks $(0.5 \mathrm{mg} / \mathrm{kg}$ per day), amoxicilline (40-50 mg/kg per day) and clarithromycin (15 $\mathrm{mg} / \mathrm{kg}$ per day) for 7 days.

Four to eight weeks after the treatment was completed, the patients with $H$. pylori infection had a follow-up endoscopy in order to assess the eradication of H. pylori (according to the Polish H. pylori Infection Workgroup consensus, 1997) ${ }^{1}$. Samples from all patients were obtained for immunohistochemistry.

To confirm the H. pylori infection we performed the following tests: rapid urease test (Clotest), Giemsa staining of the histological sections to visualise the bacteria under the optical microscope. The level of expression and localisation of $H$. pylori antigens in the gastric tissue was analysed by immunohistochemistry (immunoperoxidase and immunofluorescent method) with the use of specific antibodies (Ashton-Key et al., 1996). A child was considered to be infected with $H$. pylori when a rapid urease test and immunohistochemistry were positive. A negative status was assumed when all tests gave concordant negative results.

Immunohistochemistry. One section of a sample was immediately frozen in liquid nitrogen and stored at $-74^{\circ} \mathrm{C}$, the other one was routinely fixed in $4 \%$ phosphate-buffered formaldehyde solution and embedded in paraffin blocks according to standard procedure for immunohistochemistry and hematoxylin-eosin staining.

Immunofluorescence method. Frozen tissue sections ( $4 \mu \mathrm{m}$ thick) were incubated with polyclonal anti-H. pylori antibodies (Novocastra) (Ashton-Key et al., 1996), monoclonal antibodies to CD4, Fas/CD95, FasL (Novocastra), CD8, CD20 (Dako) and anti-IL4, IL-6, IFN $\gamma$ (Santa Cruz Biotechnology) for $16 \mathrm{~h}$ at $4^{\circ} \mathrm{C}$. The sections were incubated for $30 \mathrm{~min}$ at room temperature with fluorescein-conjugated mouse, rabbit or goat antibodies (Novocastra, Santa Cruz Biotechnology and Dako, respectively), in a dark chamber. Negative controls for each immunohistochemical staining consisted of sections in which the primary antibody had been replaced by nonimmune serum and TBS (Tris-buffered saline).

${ }^{1}$ Management of Helicobacter pylori infection (2000 year). The consensus of Polish Working Group on Helicobacter pylori of the Polish Society for Gastroenterology (2001). Pol Gastroenterol 8: 11-18 (in Polish). 
Sections were independently examined by two pathologists in four independent visual fields at 400× magnification. They were semiquantitatively scored as: 0 (negative), 1 (weakly positive), 2 (positive), and 3 (strongly positive).This scale was rearranged into a two point scale: 0 (negative) and 1 (positive).

Immunoenzymatic-PAP method. Paraffin sections of tissue samples ( $4 \mu \mathrm{m}$ thick) were fixed on silan and prepared for immunohistochemical studies after antigen retrieval $(H$. pylori by incubation with trypsin, CD4, CD8, CD20, Fas and FasL by microwave procedure). Next, slides were blocked with: protein block serum (Dako, X-09090) for detection of H. pylori, IL-4, IL-6 and IFN $\gamma$; normal rabbit serum (Dako, 0902) for detection of CD4, CD8, CD20, Fas, and FasL. Finally, sections were incubated with antibodies to: H. pylori (Novocastra, NCL-HPp) (Ashton-Key et al., 1996), CD4 (Novocastra, NCL-CD4), IL-4 (sc-6050), IL-6 (sc-1261), IFN $\gamma$ (sc-6050) (Santa Cruz Biotechnology) overnight at $4^{\circ} \mathrm{C}$ and with antibodies to: CD8 (M7103), CD20 (M07550 (Dako), Fas/CD95 (NCL-FAS-310), FasL (NCL-FAS-L) (Novocastra) $1 \mathrm{~h}$ at room temp. in a dark chamber. Antigen-antibody complexes were conjugated with peroxidase $(H$. pylori-peroxidaseconjugated rabbit immunoglobulin (Dako, P-217); IL-4, IL-6, IFN $\gamma$-biotinylated anti-rabbit/mouse/goat antibodies and peroxidase-conjugated streptavidin (LSAB System, K-4368); CD4, CD8, CD20, Fas/ CD95, FasL - rabbit anti-mouse antibody (Dako, Z-0259) and complex peroxidase-antiperoxidase of mouse serum (PAP Mouse, Dako, P-0850).

The reaction products were visualized with diaminobenzidine (DAB, Dako K-465).

The specificity of immunohistochemical staining was confirmed by negative and relevant positive controls included in each staining procedure. Sections were examined independently by two pathologists in four independent visual fields at 400x magnification and semiquantitatively scored as follows: lack of expression or very weak staining was considered as 0 , focal expression $-1,>50 \%$ of the cells stained positive for the relevant antigen -2 , and $>80 \%$ of the cells stained positive for the rele- vant antigen -3 . This scale was rearranged into a two point scale as 0 (negative) and 1 (positive).

Statistical analysis. The results of the quantitative tests were expressed as mean \pm SEM. The frequency of different antigens was compared with Pearson chi-square and McNemara chi-quare tests with Yate's correction. To test the correlation between variables we used nonparametric Spearman rank-order correlation analysis. Results were considered significant at a value of $P<0.05$. Statistical analysis was performed using Statistica (data analysis software system), version 6.0, StatSoft Inc. (USA).

The Bioethics Committee of the Medical University of Gdańsk approved the study protocol.

\section{RESULTS}

The assessment of the different lymphocyte subset participation in the gastric mucosa infiltrates was based on the percentage of patients, in whom the expression of various characteristic antigens or cytokines was found before and after the eradication. The results are presented in Table 1. Statistical analysis demonstrated that CD4 and CD20 antigens were significantly increased in group III $(H$. pylori infected patients) as compared to group IIIA (patients after eradication treatment).

In addition, there were a significantly higher number of CD20 antigens in group III in comparison to group I (patients without any signs of $H$. pylori infection and without microscopic inflammatory lesions in the gastric mucosa) and group II (patients with signs of gastritis). However, there were no significant differences between groups II and I.

We also analysed the localisation of lymphocytes within gastric mucosa. The data are shown in Table 2.

Analysis of periapoptotic markers of epithelium and lymphocytes after $H$. pylori infection is shown in Table 3.

The expression of Fas receptor was higher in H. pylori infected patients than in group I (patients

Table 1. The percentage of patients with expression of antigens characteristic for studied lymphocyte subsets in inflammatory infiltrates in gastric mucosa.

\begin{tabular}{|c|c|c|c|c|c|c|c|}
\hline \multirow[t]{2}{*}{ Number of children in studied groups $n=49$} & \multicolumn{4}{|c|}{ Lymphocyte surface antigens (\%) } & \multicolumn{3}{|c|}{ Cytokines (\%) } \\
\hline & CD3 & $\mathrm{CD} 4$ & CD8 & CD20 & IL-4 & $\operatorname{IFN} \gamma$ & IL-6 \\
\hline Group I $n=12$ & 100 & $90.9^{*}$ & 100 & $54.5^{*}$ & 91.7 & 66.7 & 83.3 \\
\hline Group II $n=10$ & 88.9 & $57.1^{*}$ & 100 & $70^{*}$ & 80 & 70 & 100 \\
\hline Group III $n=27$ & 100 & $100^{*}$ & 100 & $100^{*}$ & 80.8 & 69.2 & 96.3 \\
\hline Group IIIA n=11 & 100 & 81.8 & 100 & 81.8 & 81.8 & 54.5 & 100 \\
\hline
\end{tabular}

${ }^{*} P<0.05$ 
Table 2. Analysis of different lymphocyte subset antigens in gastric mucosa.

\begin{tabular}{lllllll}
\hline Lymphocyte surface antigens and cytokines & $\begin{array}{l}\text { CD4 } \\
(\%)\end{array}$ & $\begin{array}{l}\text { CD8 } \\
(\%)\end{array}$ & $\begin{array}{l}\text { CD20 } \\
(\%)\end{array}$ & $\begin{array}{l}\text { IL-4 } \\
(\%)\end{array}$ & $\begin{array}{l}\text { INF } \gamma \\
(\%)\end{array}$ & $\begin{array}{l}\text { IL-6 } \\
(\%)\end{array}$ \\
\hline Superficial localisation & $\mathbf{1 6 . 3}$ & 83.7 & $\mathbf{1 4 . 3}$ & 75.5 & $\mathbf{3 2 . 7}$ & 93.9 \\
Deep localisation & $\mathbf{8 1 . 6}$ & 100 & $\mathbf{7 9 . 6}$ & $\mathbf{6 9 . 4}$ & $\mathbf{6 1 . 2}$ & 91.8 \\
\hline
\end{tabular}

Table 3. The percentage of patients with expression of selected periapoptotic markers in gastric mucosa.

\begin{tabular}{lll}
\hline $\begin{array}{l}\text { Number of children in studied } \\
\text { groups } n=43649\end{array}$ & \multicolumn{2}{l}{$\begin{array}{l}\text { Periapoptotic markers } \\
(\%)\end{array}$} \\
\cline { 2 - 3 } & Fas & FasL \\
\hline Group I $n=12$ & $41.7^{*}$ & 100 \\
Group II $n=10$ & $33.3^{*}$ & 100 \\
Group III $n=27$ & $77.8^{*}$ & 100 \\
Group IIIA $n=11$ & 36.4 & 90 \\
\hline
\end{tabular}

${ }^{*} \boldsymbol{P}<0.05$

Table 4. Analysis of the localisation of selected periapoptotic markers.

\begin{tabular}{lll}
\hline Periapoptotic markers & Fas (\%) & FasL (\%) \\
\hline Superficial localisation & 6.25 & 97.3 \\
Deep localisation & 77.1 & 97.3 \\
\hline
\end{tabular}

with normal histopathological examination result and without $H$. pylori infection). Similarly, the Fas receptor expression was significantly different in group III (H. pylori infected children) than in group II (patients with chronic gastritis, without $H$. pylori infection). Statistical analysis showed significantly increased expression of Fas receptor in group II as compared to group IIIA. After eradication treatment children from group IIIA had significantly decreased expression of Fas receptor, which was comparable to the level in group I and II (Table 3).

Similarly to the lymphocyte subset localisation, we analysed the localisation of selected periapoptotic markers. The data are shown in Table 4.

The analysis of Fas and FasL receptor localisation showed that Fas receptor was localised in lamina propria in a high percentage of patients (Table 4).

In order to specify further which of the lymphocyte subsets may be the subject of enhanced apoptosis induction caused by $H$. pylori we analysed whether there was a correlation between examined lymphocytic subpopulations and Fas and FasL receptors. The data are shown in Table 5.

We found that in $H$. pylori infected patients, there is a positive correlation $(R=0.436, P<0.05)$ between CD4 antigen expression, characteristic for T helper lymphocytes, and Fas receptor expression - one of the periapoptotic markers.

\section{DISCUSSION}

The problem of H. pylori infection in paediatric population is still to be investigated (Ernst \& Gold, 1999; Luzza et al., 2000). Recently, a number of studies pointing towards Th1 lymphocytes as the dominat subpopulation in the gastric mucosa, both in adults and children were published (Suerbaum et al., 2002; Luzza et al., 2000; Maciorkowska et al.,

Table 5. Analysis of correlation of lymphocyte subsets with Fas and FasL receptors in H. pylori infected patients.

\begin{tabular}{lcll}
\hline Antigens & Number of patients in group III n=27 & $\mathrm{R}_{\mathrm{S}}$ & $P$ \\
\hline CD 3 \& Fas & 23 & 0.128 & 0.56 \\
CD 3 \& FasL & 14 & 0.112 & 0.70 \\
CD 4 \& Fas* & 23 & 0.436 & $0.04^{*}$ \\
CD 4 \& FasL & 14 & 0.018 & 0.95 \\
CD 8 \& Fas & 24 & 0.202 & 0.34 \\
CD 8 \& FasL & 15 & 0.059 & 0.83 \\
CD 20 \& Fas & 23 & 0.099 & 0.65 \\
CD 20 \& FasL & 15 & 0.313 & 0.26 \\
\hline
\end{tabular}


1999; Sommer et al., 1998). Our study demonstrates that CD8 T cytotoxic/suppressor lymphocyte antigens were present in almost all patients from the study population. IFN $\gamma$, characteristic for Th1 lymphocytes, was present in more than $50 \%$ of patients; IL-4 and IL-6 secreted by Th2 lymphocytes were found in $80 \%$ and $90 \%$ of children, respectively. There were no statistically significant differences in secretion of those cytokines among the studied groups of patients. Similarly to CD3 and CD8 $\mathrm{T}$ lymphocytes, $\mathrm{T}$ helper lymphocytes (CD4) and $\mathrm{B}$ lymphocytes (CD20) were frequent in the inflammatory infiltrates of the gastric mucosa biopsies. We found that the B lymphocyte subset was significantly more common in $H$. pylori infected patients than in group I or group II (patients without H. pylori infection) (Maciorkowska et al., 1999; Bussiere et al., 2006). Interestingly, the percentage of CD20 mononuclear cells was markedly reduced in the studied population after eradication treatment. There was a statistically significant decrease in the percentage of CD4 lymphocytes in $H$. pylori infected patients after eradication as compared to the group of patients before treatment.

What is important, we confirmed the major contribution of Th lymphocyte (CD4) subpopulation in the inflammatory infiltration in the gastric mucosa of $H$. pylori infected children. It was, however, impossible to specify the lymphocyte subtype: Th1 or Th2.

There are two theories concerning H. pylori influence on apoptosis of lymphocytes in gastric mucosa. Studies based on the material obtained from adult patients indicate that $H$. pylori might delay spontaneous lymphocyte apoptosis and prolong survival of these cells. It results in the prolonged action of cytokines secreted by these cells and therefore augments their damaging action upon gastric mucosa (Moss et al., 1996; Bussiere et al., 2006). The findings of other authors suggest that $H$. pylori infection may accelerate the programmed death of immunocompetent cells or even inhibit proliferation of T-cells; hence they cannot eliminate the bacteria (Schmees et al., 2007; Wang et al., 2001; Houghton et al., 1999).

New studies suggest that the presence of $H$. pylori stimulates apoptosis of gastric mucosal epithelial cells and lymphocytes via two different pathways: membrane involving so called "death receptors" (Fas and FasL) and mitochondrial involving cytochrome c/Apaf-1, Bcl-2 proteins (Bland et al., 2006; Konturek et al., 2003; Moss et al., 1996). The expression of Fas receptor in healthy gastric mucosa is low (Houghton et al., 1999; Konturek et al., 2003). The enhanced expression of Fas antigen on epithelial cells and lymphocytes and of Fas ligand receptor on lymphocytes may be a result of the action of IFN $\gamma$, which is a cytokine secreted mainly by Th1 helper lymphocyte subset (Moss et al., 1996). In our study, we investigated the expression of Fas and FasL antigens and we found that Fas antigen expression on epithelial cells and gastric mucosal lymphocytes was the highest in H. pylori infected patients and significantly decreased after eradication. Our results are consistent with other published data, which highlight the crucial role of $H$. pylori antigen in Fas receptor expression on the cell surface and therefore emphasise the increased possibility of apoptosis stimulation depending on the expression of this receptor. Moreover, the possibility of programmed cell death reduction is present even after eradication treatment (Wang et al., 2000). We found a very high expression of FasL receptor in all groups of investigated patients, slightly lower in patients after eradication treatment. This receptor is absent on lymphocytes under physiological conditions (Houhgton et al., 1999; Konturek et al., 2003). Such a high expression of FasL receptors in our study population may be a result of lymphocytic infiltration, the presence of which was confirmed by immunohistochemistry in all studied groups. The interaction between so called "death receptors" (Fas, FasL) is a signal which may trigger apoptosis in cells expressing these receptors. According to some authors, the expression of FasL receptor in gastric mucosa is mainly related to $H$. pylori infection (Ishihara et al., 2001; Souza et al., 2006). Our results did not confirm these observations. We found that an increase in expressions of FasL receptor may also be caused by the inflammatory process in gastric mucosa without $H$. pylori infection.

To sum up, we found that in the studied paediatric population $H$. pylori infection significantly enhances the level of Fas receptor expression on the cell surface and thus augments the possibility of entering apoptosis induction phase by these cells.

To answer the question which of the lymphocyte subsets mainly undergoes apoptosis, we analysed the correlation between the differentiation antigens of various lymphocyte subsets with Fas and FasL receptors in the group of H. pylori infected children. There was a correlation between CD4 antigen of $\mathrm{T}$ helper cells and Fas receptor. This suggests that the gastric mucosa $\mathrm{T}$ lymphocytes are the subpopulation that may predominantly enter apoptosis induction phase during $H$. pylori infection in children. Similar results were reported by other authors (Wang et al., 2000; 2001; Koyama, 2000).

\section{CONCLUSIONS}

The increased apoptosis of T helper cells may be the cause of persistent infection without eliminating the bacteria from the patient's organism. The 
presented results may confirm that $H$. pylori evades immunosurveillance by the programmed death of immunocompetent cells, especially CD4 helper lymphocytes.

\section{REFERENCES}

Ashton-Key M, Diss TC, Isaacson PG (1996) Detection of Helicobacter pylori in gastric biopsy and resection specimens. J Clin Pathol 49: 107-111.

Bland DA, Suarez G, Beswick EJ, Siera JC, Reyes VE (2006) Helicobacter pylori receptor MHC class II contributes to the dynamic gastric epithelial apoptotic response. World I Gastroenterol 12: 4689-4693.

Bussiere FI, Chaturvedi R, Asim M (2006) Low multiplicity of infection of Helicobacter pylori suppresses apoptosis of B lymphocytes. Cancer Res 66: 6834-6842.

Dixon MF, Genta RM, Yardley JH, Correa P (1996) Classification and grading of gastritis. The updated Sydney System. Am J Surg Pathol 20: 1161-1181.

Dohil R, Hassall E, Jevon G, Dimmick J (1999) Gastritis and gastropathy of childhood. I Pediatr Gastroenterol Nutr 29: 378-394.

Ernst PB, Gold BD (1999) Helicobacter pylori in childhood: new insights into the immunopathogenesis of gastric disease and implications for managing infection in children. J Pediatr Gastroenterol Nutr 28: 462-473.

Houghton J, Korah RM, Condon MR, Kim KH (1999) Apoptosis in Helicobacter pylori-associated gastric and duodenal ulcer disease is mediated via the Fas antigen pathway. Dig Dis Sci 44: 465-478.

Ishihara S, Fukuda R, Kawashima K, Moriyama N, Suetsugu $H$, Ishimura $N$, Kazumori $H$, Kaji $T$, Sato $H$, Okuyama T, Rumi K, Adachi K, Watanabe M, Kinoshita Y (2001) T cell-mediated cytotoxicity via Fas/Fas ligand signaling in Helicobacter pylori-infected gastric corpus. Helicobacter 6: 283-293.

Konturek PC, Kania J, Kukharsky V, Ocker S, Hahn EG, Konturek SJ (2003) Influence of gastrin on the expression of cyclooxygenase-2, hepatocyte growth factor and apoptosis-related proteins in gastric epithelial cells. J Physiol Pharmacol 1: 17-32.

Koyama S (2000) Apoptotic depletion of infiltrating mucosal lymphocytes associate with Fas ligand expression by Helicobacter pylori-infected gastric mucosal epithelium: human glandular stomach as a site of immune privilege. Dig Dis Sci 45: 773-780.

Krauss-Etschmann S, Gruber R, Plikat K, Antoni I, Demmelmair H, Reinhardt D, Koletzko S (2005) Increase of antigen-presenting cells in gastric mucosa of Helicobacter pylori-infected children. Helicobacter 10: 214-222.

Luzza F, Parrello T, Sebkowa L, Pensabene L, Imeneo M, Mancuso M, La Vecchia AM, Monteleone G, Strisciug- lio P, Pallone F (2000) Expression of proinflammatory and Th1 but not Th2 cytokines is enhanced in gastric mucosa of Helicobacter pylori infected children. Digest Liver Dis 33: 14-20.

Maciorkowska E, Kaczmarski M, Kemona A (1999) Concentration of selected cytokines of gastric mucosa in children with Helicobacter pylori infection. Med Sci Monit 5: 1140-1145.

Misiewicz JJ, Tytgat GNJ, Goodwin CS, Price AB, Sipponen P, Strickland RG, Cheli R (1994) The Sydney System: a new classification of gastritis. Working Party Reports, 1990 (Polish translation in Pract Med 9: 89-98).

Moss SF, Calam J, Agrawal B, Wang S, Holt PG (1996) Induction of gastric epithelial apoptosis by Helicobacter pylori. Gut 38: 498-501.

Schmees C, Prinz C, Treptau T, Rad R, Hengst L, Voland $\mathrm{P}$, Bauer S (2007) Inhibition of T-cell proliferation by Helicobacter pylori gamma-glutamyl transpeptidase. Gastroenterol 132: 1820-1833.

Singh M, Prasad KN, Krishnani N, Saxena A, Yachha SK (2006) Helicobacter pylori infection, histopathological gastritis and gastric epithelial cell apoptosis in children. Acta Paediatr 95: 732-737.

Sommer F, Faller G, Konturek P, Kirchner T, Hahn EG, Zeus J, Rollinghoff M, Lohoff M (1998) Antrum- and corpus mucosa-infiltrating CD4 lymphocytes in Helicobacter pylori gastritis display a Th1 phenotype. Infect Immun 66: 5543-5546.

Souza H, Neves M, Elia C, Tortori C, Dines I, Martinusso C, Madi K, Andrade L, Castelo-Branco M (2006) Distinct patterns of mucosal apoptosis in $H$. pylori-associated gastric ulcer are associated with altered FasL and perforin cytotoxic pathways. World J Gastroenterol 12: 6133-6141.

Suerbaum S, Michetti P (2002) Helicobacter pylori infection. $N$ Eng J Med 347: 1175-1186.

The Consensus of Polish Working Group on Helicobacter pylori (1997) Pol Gastroenterol 6: 635-640 (in Polish).

Tytgat GNJ (1992) Short term and long term consequences of gastritis/duodenitis-preface. Eur J Gastroenterol Hepatol 4 (Suppl 2): 1.

Wang J, Fan X, Lindholm C, Bennett M, O'Connoll J, Shanahan F, Brooks EG, Reyes VE, Ernst PB (2000) Helicobacter pylori modulates lymphoepithelial cell interactions leading to epithelial cell damage through Fas/Fas ligand interactions. Infect Immun 68: 4303-4311.

Wang J, Brooks EG, Bamford KB, Denning TL, Pappo J, Ernst PB (2001) Negative selection of T cells by Helicobacter pylori as a model for bacterial strain selection by immune invasion. Immunol 167: 926-934.

Wisniewski P, Master A, Kaminska B (2008) Cloning and purification of functionally active Fas ligand interfering protein (FIP) expressed in Escherichia coli. Acta Biochim Polon 55: 51-56. 